\title{
Concept and Evaluation of Ecosystem Intrinsic Value
}

\author{
Luo Ping Zhang, Hong Ni Xu, Hua Xia Sheng, Wei Qi Chen and Qin Hua Fang \\ The College of the Environment and Ecology, Xiamen University, Xiamen, Fujian 361102, China
}

\begin{abstract}
Ecosystem valuation can serve as a basis of scientific support for decision-making. So far, the most popular methods for ecosystem valuation are ecosystem service valuation (ESV), which is based on the utility of ecosystem to human beings rather than on the objective value of the ecosystem. After more than 10 years' application, it has been found that all losses of ESV were about $10 \%$ of the benefits of human activities. In this paper, the ecosystem intrinsic value (EIV) is defined. EIV is an objective value that emerges from the existence, structures, functions and processes of ecosystem, but independent with man, man's will and preferences. The valuating approach and methods used for EIV were developed by using energy approach and the methods of emergy analysis and eco-exergy analysis. The EIV calculated by emergy from the substance, energy and information of ecosystem and by eco-exergy from the structure and function of ecosystem represents the existent value and the externally working capacity of ecosystem, respectively. The approach and methods of EIV evaluation were applied to Xiamen Bay, China. The results showed that the marine EIV in Xiamen Bay was 209 billion RMB, including 116 billion RMB of emergy and 92.4 billion RMB of eco-exergy in 2010, nearly 30 times of ESV and 8.5 times of the GDP of Xiamen marine industry in 2010. The EIV in unit area of Xiamen Bay is more than 10 times higher than the average global ESV in estuaries. It implied a potential undervaluation to ecosystem value by ESV calculation, which may mislead decisions-making processes.
\end{abstract}

Key words: Ecosystem intrinsic value, concept, evaluation, approach, methods.

\section{Introduction}

Ecosystem services represent the benefits human populations derive, directly or indirectly, from ecosystem goods and services together, which was defined by Costanza et al. in 1997 [1]. These services were considered to bridge ecology, economy and social science [2], and became a powerful tool and popular approach to support decision-making processes all over the world since then.

Ecosystem services were grouped into 17 major categories, and the approaches and methods for their valuation were synthesized based on previous studies by Costanza et al. [1]. Many of the valuation techniques used in the synthesis are based, either directly or indirectly, on attempts to estimate the "willingness-to-pay" of individuals for ecosystem services [1].

The approach and methods of ecosystem service value (ESV) have been applied into many case studies

Corresponding author: Luo Ping Zhang, professor, research fields: environmental planning and management. to support decision-making towards sustainability, for example, the strategic environmental assessment (SEA) for regional development planning in 1998-2000 [3, 4], SEA of harbor planning in 2000-2002 [5], marine environmental capacity in 2000-2002 [6], SEA for marine reclamation planning in 2005-2007 [7], SEA of hydropower development planning in watershed in 2006-2007 [8] and coastal principal function zoning (similar to marine spatial planning) in 2009-2012 [9]. After more than 10 years' application, however, it was found that most losses of ESV were only 5\%-20\% (average about 10\%) of the benefits of human development activities, except in the SEA of hydropower development, where ESV losses were up to $64 \%-91 \%$, but still less than their benefits [8]. These results from ESV would be hard to stop the crazy development of mankind, hard to effectively conserve ecosystem health and ecological security, and could not guide decision-making towards sustainability. Despite a number of ESV-inspired sustainability initiatives since the 1990s, global ecological degradation continues to accelerate. This 
suggests that ESV has fallen far short of its goals of sustainable social transformation [10].

We have to rethink the ecosystem value its due, and argue that ESV may undervalue the ecosystem and nature's value. The purpose of this article was to define the concept of ecosystem intrinsic value (EIV) and propose the approach and methodology for the evaluation of EIV.

\section{Description, Concept and Methods}

\subsection{Argument of Ecosystem Value}

The problem of intrinsic value has been a central debate in ethics for nearly a century. Dietz et al. [11] reviewed former researches on it and concluded that: (1) in philosophy, values are relatively stable principle that help us make decisions when our preferences are in conflict and thus convey some sense of what we consider good; (2) in economics, the term values are usually used in discussions of social choice under a utilitarian ethic; (3) in sociology, social psychology and political science, values can be difficult to understand without some attention to how individual values relate to other important influences on individual behavior, such as beliefs, norms and attitudes [11].

The concept of ecosystem services, defined by Fisher et al. in 2008 as "the aspects of ecosystems utilized (actively or passively) to produce human well-being”, only becomes anthropocentric in the moral sense, and covers by definition only nature's instrumental values as a means to the end of human well-being [12].

O'Neill [13] concluded three senses of intrinsic value: (1) non-instrumental value (an end value, not a means/use value); (2) non-relational value (a value not a function of relationship); (3) objective value (not a function of a subjective, conscious valuing). The Millennium Ecosystem Assessment (MA) [14] stated that "intrinsic value is the value of something in and for itself, irrespective of its utility for someone else. Sound ecosystem management thus involves steps to address the utilitarian links of people to ecosystems as well as processes that allow considerations of the intrinsic value of ecosystems to be factored into decision-making”. The report of The Economics of Ecosystems and Biodiversity (TEEB) [15] stated that "the issue of intrinsic values is helpful to reflect on the relationship between nature and humans. It proposes that nature has value in itself and is valued as an end in itself, independent of its usefulness to achieve some higher end. Therefore, acknowledging intrinsic values of nature acknowledges the fact that people are part of nature”.

In a word, from the view of economists, no use would be no value (adopt anthropocentric perspectives that focus on instrumental values [15]); and from the view of environmental ethicists, existence is value (biocentric perspectives based on intrinsic ecological values [15]). From the authors' understanding, ESV is based on the eye of mankind to see the world, and is thereby the subjective value of mankind. We need to stand on the eye of nature to see natural world and to get objective value of nature and ecosystem.

The authors do not want to join the arguments about ESV and EIV, and it is hard to recognize the philosophic issues, such as anthropocentric, egocentric, utilitarian and naturalistic viewpoints, and so on. But, they agree with MA's viewpoint that nature or ecosystems have intrinsic value, independent of their contribution to human well-being [14]. Intrinsic values are culturally embedded moral truths [15].

The authors believe that ESV represents instrumental and utility value of ecosystem to human being. It is based on the utility from human perspective, not based on ecosystem itself, and relates to ecosystem functions that are used to human, rather than the full objective value of ecosystem. Economic valuation of ecosystem services has been variously criticized by different commentators [14]. In contrary, EIV bases on ecosystem itself, its existence, and is an objective value of ecosystem itself. Existence of ecosystem is a basis, and ESV is only the working 
process of ecosystem functions to human being. No existence would be no service.

\subsection{Definition and Implications of EIV}

The concept of EIV is defined in this article. EIV is the objective value represented solely by ecosystem itself and its nature, independent with man, man's will and preferences, i.e., human market or society.

An ecosystem is a community of living organisms in conjunction with the nonliving components of their environment, interacting as a system, and includes ecological interactions and processes in ecosystem structure and function [16]. These biotic and abiotic components are regarded as linked together through nutrient cycles and energy flows. Energy, water, nitrogen and soil minerals are other essential abiotic components of an ecosystem. The energy that flows through ecosystems is obtained primarily from the sun [16]. Biodiversity affects ecosystem function, as do the processes of disturbance and succession [16] and overall indicators of ecosystem states and distributions for measures of information [17]. Ecosystem communities are structured by networks of interactions, in which species are the nodes and biotic interactions are the links. The links reflect exchanges or transfers of energy and material among interacting organisms [18].

The implication of EIV is identified according to the definitions of ecosystem and EIV. EIV could be expressed by the existence, structures, functions and processes of ecosystem, including the sum of substance, energy and information of ecosystem.

\subsection{Approach and Methods for Evaluating EIV}

\subsubsection{Methods of Evaluation}

The valuation methods themselves are designed in a way and emerge from the understanding of what values are, or should be and how they can be elicited [15]. TEEB, although acknowledges the importance of nature's intrinsic worth, does not explicitly address intrinsic values of nature, including the ethical considerations regarding the rights of all species [15]. The willingness to pay depends greatly on the socio-economic context, in which valuation takes place on human preferences, institutions, culture and so on. Intrinsic values are culturally embedded. They can be taken into account by choosing the appropriate institutions [15]. There are no widely accepted methods for systematically quantifying intrinsic value [11].

Energy is a quantity common to all processes; it flows, is stored and is transformed in form. Energy is used as a common measure of all kinds of activity, and the flows of information carry the most embodied energy [17]. According to this concept and the definitions of ecosystem and EIV, the energy approach, standing in the eye of nature to objectively express ecosystem and its structures, functions and processes, would be the best way to evaluate EIV at this stage.

The biophysical methods for the valuation or accounting of natural capital are embodied as energy analysis (Costanza 1980), emergy analysis (Odum 1996), exergy analysis (Naredo, 2001; Jørgensen et al., 2005), ecological footprint (Wackernagel et al., 1999), material flow analysis (Daniels and Moore, 2002), land-cover flow (EEA, 2006) and human appropriation of net primary production (HANPP) (Schandl et al., 2002) [15]. After reviewing these methods and the entropy method, the authors have come to conclusion that the methods of emergy analysis and eco-exergy analysis could be used for the evaluation of EIV, which are all following energy approach.

2.3.2 Method of Emergy Analysis for Valuating EIV

An energy theory of value is based on embodied energy. Embodied energy can be as a measure of value [17]. Emergy is defined as the energy of one type required in transformations to generate a flow or storage [19]. Emergy is a type of available energy, embodied energy in a system that is consumed in 
direct and indirect transformations needed to make a product or service and accounts for a measure of quality differences between different forms of energy [20]. Emergy is measured in units of emjoules, a unit referring to the available energy of one kind consumed in transformations [20]. Emergy analysis is a technique of quantitative analysis, which determines the value of non-monied and monied resources, services and commodities in common units of the solar energy based on the principles of energetics, system theory and systems ecology; and transformity is defined as emergy input per unit of available energy (exergy) output [21].

Odum [20] proposed the methods of emergy analysis as Eq. (1):

$$
\begin{gathered}
E m=E n \times \tau \\
\text { or } E m=m \times \tau \\
\text { or } E m=S p \times \tau
\end{gathered}
$$

where, $E m$ is emergy (sej); $E n$ is available energy (J); $m$ is mass of substance (g); $S p$ is species number; $\tau$ is transformity of available energy (sej/J) or substance (sej/g) or species (sejs/pecies), respectively. Sola transformity for many types of energy, biological species and commodities was derived by Odum [20] and relative researches.

Emergy could be monetized according to Odum [20] by Eq. (2):

$$
E m \$=E m / E m R
$$

where, $E m \$$ is a measure of the money of emergy (money unit such as \$), in practice, the emergy is multiplied by the ratio of total emergy to gross national product (GNP) for the national economy [22]; $E m R$ is the ratio of emergy and GNP (sej/\$). More details for emergy analysis can refer to relative references, especially from $\mathrm{H}$. T. Odum.

In the authors' analysis, emergy value embodies the existence value of EIV from its definition of embodied energy.

2.3.3 Method of Eco-exergy Analysis for Valuating EIV

In thermodynamics, the exergy of a system is the maximum useful work possible during a process that brings the system into equilibrium with a heat reservoir, available energy to work [23]. Exergy is defined as the amount of work that a system can perform when it is brought into thermodynamic equilibrium with its environment [24, 25]. Information is also a convenient measure of physical structure. On the more complex level, information may still be strongly related to exergy but in more indirect ways [25]. Eco-exergy is defined as the work capacity of an ecosystem compared with the same system at thermodynamic equilibrium and at the same temperature and pressure [26]. It can be shown that eco-exergy measures biomass and information. Eco-exergy seems therefore a proper measure of biological and ecological complexity and thereby the evolution [26]. Eco-exergy could be considered as a potential, available and maximum useful work of an ecosystem.

S. E. Jørgensen and his colleagues [24-27] proposed the methods of eco-exergy analysis in ecology. Eco-exergy density can be calculated by Eq. (3) [27]:

$$
E x_{\text {density }}=18.7 \sum \beta_{i} C_{i}
$$

The total eco-exergy in a given area could be simply got, using eco-exergy density multiplying by the turnover rates and the areas of components as Eq. (4) [28]:

$$
E x_{\text {total }}=18.7 \sum \beta_{i} C_{i} R_{i} S_{i}
$$

where, $E x_{\text {density }}$ and $E x_{\text {total }}$ is eco-exergy density $\left(\mathrm{kJ} / \mathrm{m}^{2}\right)$ and total eco-exergy $(\mathrm{kJ}) ; 18.7$ is the exergy contributed by detritus, dead organic matter $(\mathrm{kJ} / \mathrm{g}) ; \beta$ is a weighting factor considering what the probability is to form the organism at thermodynamic equilibrium ( $\mathrm{kJ} / \mathrm{g}$ ) [27], and Jørgensen et al. [24] proposed the best $\beta$ values for main species; $i$ is a component; $C_{i}$ is the concentration of a component $\left(\mathrm{g} / \mathrm{m}^{2}\right) ; R_{i}$ is the turnover rate of a component (times/year); and $S_{i}$ is the area of a component occupied $\left(\mathrm{m}^{2}\right)$.

According to method of emergy and Jørgensen's results by using energy costs [29], the eco-exergy could be monetized by Eq. (5) [28]: 


$$
E x \$=E x_{\text {total }} \times E x R
$$

where, $E x \$$ is a measure of the money of eco-exergy (money unit, such as \$); ExR is the ratio of GNP and eco-exergy $(\$ / \mathrm{kJ})$.

In the authors' analysis, eco-exergy value embodies the potential work capacity of ecosystem from the definitions of exergy and eco-exergy, a creative value of EIV.

\subsection{Case Study}

\subsubsection{Profile of Xiamen Bay Case Study Area}

Xiamen Bay, located in the Southeast of Fujian Province, China, is a typical subtropical coastal ecosystem. It is a semi-enclosed bay with seven coastal subunits: Jiulong River Estuary, Western Seas, Southern Seas, Eastern Seas, Tongan Bay, Dadeng Seas and Weitou Bay.

The scopes of the bay, and its subunits and coastal area were determined following the principle of ecosystem-based management. The total marine area is about $984 \mathrm{~km}^{2}$ (Fig. 1).

\subsubsection{Data Collection, Assessment and Evaluation}

Assumption was proposed that marine ecosystem in Xiamen Bay was in dynamic equilibrium within a year, such as 2010, the research baseline year.

All available data were collected, including all abiotic and biotic data for marine ecosystem of Xiamen Bay, and relative socio-economic information in its coastal area, most of them for more than 10 years and some for more than 20 years, such as the data for marine environmental monitoring and relative socio-economic information starting from the end of 1980s.

The retrospective assessments were done for the subunits and whole bay to understand the status and trends of the ecosystem, and the impact of human activities from the coastal area of the bay on the marine ecosystem.

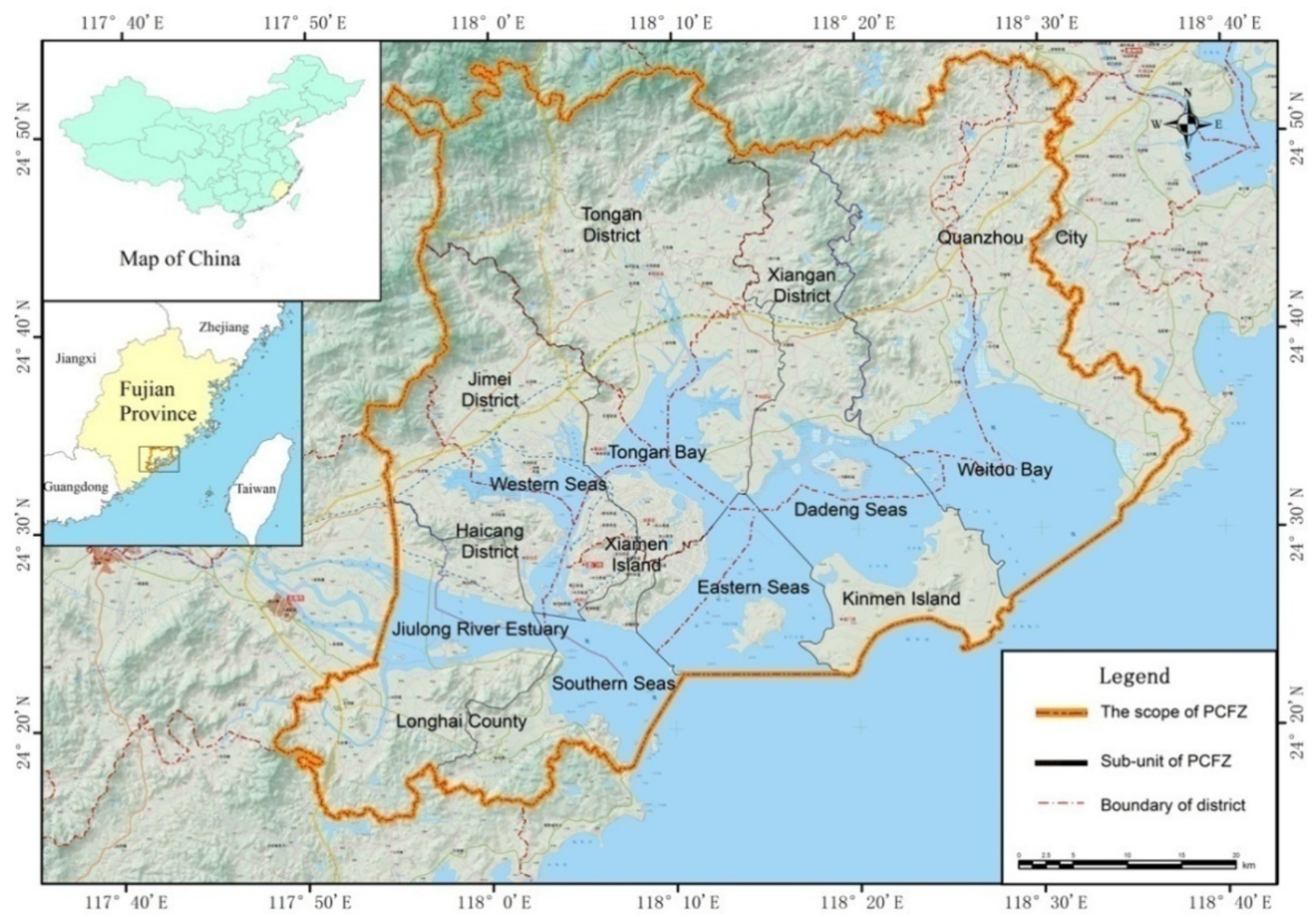

Fig. 1 Scope of coastal ecosystem in Xiamen Bay. 
The emergy and eco-exergy of EIV in the marine area of Xiamen Bay was calculated by using Eqs. (1), (3) and (4), and monetized by Eqs. (2) and (5), respectively [28].

\section{Results and Discussion}

The results calculated by emergy analysis and eco-exergy analysis in the marine ecosystem of Xiamen Bay in 2010 [28] were presented in Table 1 and Table 2, respectively.

The emergy of marine ecosystem in Xiamen Bay $\left(984 \mathrm{~km}^{2}\right)$ was $1.48 \times 10^{23}$ sej, and the money of emergy $(E m \$)$ was more than 116 billion RMB (Chinese currency). The abiotic components contributed about 2.7\%, biotic components contributed about $3.7 \%$, and biodiversity accounted for nearly 94\% of the emergy. TEEB [15] emphasized that "biodiversity plays an important role in fostering a sense of place in most societies and has considerable intrinsic cultural value". According to the definition of emergy - available and embodied energy, the authors define the ecosystem emergy to be the existence value of an ecosystem in steady state or the state of dynamic equilibrium, the basis of EIV.

The eco-exergy of marine ecosystem in Xiamen Bay in 2010 was $9.67 \times 10^{14} \mathrm{~kJ}$, and the money of eco-exergy ( $E x \$)$ was 92.4 billion RMB. According to the definition of eco-exergy-work capacity of ecosystem, the authors define the eco-exergy to be the potential, available and maximum useful work of an ecosystem in a given period, a creative value of EIV.

Considering the sum of existence value and work capacity of ecosystem, total EIV of marine ecosystem in Xiamen Bay in 2010 was about 209 billion RMB [28]. The existence value accounted for more than 55\% of total EIV, and work capacity contributed more than $44 \%$ of EIV.

The ESV of marine ecosystem in Xiamen Bay in 2010 calculated by the commonly used methods of
ESV was 7.08 billion RMB [9], and the GDP of marine industry of Xiamen city in 2010 was 24.7 billion RMB [28]. When the monetized EIVs, including total EIV and eco-exergy (work capacity), compared with the ESV and the GDP, the total EIV is nearly 30 times of the ESV and 8.5 times of the GDP of Xiamen marine industry in 2010, very close to the “ten percent” of Lindeman's efficiency. Eco-exergy of EIV is 13 times and 3.7 times of the ESV and GDP of Xiamen marine industry in 2010, respectively. It is theoretically unreasonable that ESV is much lower than the GDP (less than 30\% of GDP). The work capacity of EIV $(E x \$)$, however, is 3.7 times of the GDP, a more reasonable result in natural and socio-economical system from a scientific point of view.

Costanza et al. [1] calculated the average global ESVs of all typical ecosystems. The highest ESV in unit area in the world was estuaries, 22,832 \$/ha/year in 1994, which could be converted to $3.16 \times 10^{6}$ $\$ / \mathrm{km}^{2} /$ year in 2010 with USA's GDP deflator [9]. The EIV in unit area of Xiamen Bay in 2010 was $212 \times$ $10^{6} \mathrm{RMB} / \mathrm{km}^{2} /$ year $=34 \times 10^{6} \$ / \mathrm{km}^{2} /$ year, more than 10 times of average ESV in estuaries.

From these results, very low value by ESV calculation was found relative to EIV. It implies that ESV may undervalue the ecosystem value. The willingness-to-pay would award these a low or negligible value [30].

After reviewing the concepts and approaches of ESV and EIV, the authors recognize that both of them are intrinsically different in viewpoint and approach. ESV is based in the eye of mankind to see the world, and uses market or non-market approach from human perspective. Therefore, ESV is a subjective value of ecosystem from the perspective of mankind. On the contrary, EIV stands in the eye of nature to see natural world, and uses natural approach from ecosystem itself. EIV value, therefore, is an objective one. 
Table 1 Emergy analysis of marine ecosystem in Xiamen Bay[28].

\begin{tabular}{|c|c|c|c|c|c|}
\hline Components & $\begin{array}{l}\text { Dry weight } \\
\left(\mathrm{g} / \mathrm{m}^{2}\right)\end{array}$ & $\begin{array}{l}\text { Total energy } \\
(\mathrm{J})\end{array}$ & $\begin{array}{l}\text { Emergy transformity } \\
\tau \text { (sej/unit) }\end{array}$ & $\begin{array}{l}\text { Emergy } \\
\text { (sej) }\end{array}$ & $\begin{array}{l}\text { Emergy dollar } \\
\text { (RMB) }\end{array}$ \\
\hline Abiotic component & & & & $3.71 \times 10^{21}$ & $3.15 \times 10^{9}$ \\
\hline Solar energy & - & $4.81 \times 10^{18}$ & 1 & $4.81 \times 10^{18}$ & $3.78 \times 10^{6}$ \\
\hline Wind energy & - & $3.05 \times 10^{15}$ & 663 & $2.02 \times 10^{18}$ & $1.59 \times 10^{6}$ \\
\hline Rainfall (chemical energy) & - & $6.81 \times 10^{15}$ & 15,444 & $1.05 \times 10^{18}$ & $8.25 \times 10^{7}$ \\
\hline Tidal energy & - & $5.58 \times 10^{16}$ & 23,564 & $1.31 \times 10^{21}$ & $1.03 \times 10^{9}$ \\
\hline Wave energy & - & $7.20 \times 10^{16}$ & 30,550 & $2.20 \times 10^{21}$ & $1.73 \times 10^{9}$ \\
\hline Sediment & - & $3.47 \times 10^{14}$ & 74,000 & $2.57 \times 10^{19}$ & $2.02 \times 10^{7}$ \\
\hline Seawater & - & $3.05 \times 10^{16}$ & 48,00 & $1.47 \times 10^{20}$ & $1.15 \times 10^{8}$ \\
\hline Macronutrients (N, P) & - & - & - & $2.30 \times 10^{19}$ & $1.80 \times 10^{7}$ \\
\hline Biodetritus & $1.04 \times 10^{3}$ & $1.71 \times 10^{16}$ & 11,000 & $1.88 \times 10^{20}$ & $1.48 \times 10^{8}$ \\
\hline Bio-components & & & & $5.37 \times 10^{21}$ & $4.25 \times 10^{9}$ \\
\hline Phytoplankton & 3.36 & $5.54 \times 10^{13}$ & 4,700 & $2.60 \times 10^{17}$ & $2.04 \times 10^{5}$ \\
\hline Mangroves & $4.89 \times 10^{4}$ & $1.72 \times 10^{15}$ & 4,700 & $8.11 \times 10^{18}$ & $6.36 \times 10^{6}$ \\
\hline Zooplankton & 0.106 & $2.09 \times 10^{12}$ & $1.68 \times 10^{5}$ & $3.50 \times 10^{17}$ & $2.75 \times 10^{5}$ \\
\hline Macrobenthos & 7.52 & $1.08 \times 10^{14}$ & $1.30 \times 10^{7}$ & $1.40 \times 10^{21}$ & $1.10 \times 10^{9}$ \\
\hline Macrobenthos (intertidal) & 138 & $2.96 \times 10^{14}$ & $1.30 \times 10^{7}$ & $3.85 \times 10^{21}$ & $3.02 \times 10^{9}$ \\
\hline Meiofauna & 0.046 & $7.58 \times 10^{11}$ & $1.30 \times 10^{7}$ & $9.85 \times 10^{18}$ & $7.73 \times 10^{6}$ \\
\hline Fish & 0.144 & $3.26 \times 10^{12}$ & $3.10 \times 10^{7}$ & $1.01 \times 10^{20}$ & $7.94 \times 10^{7}$ \\
\hline Siphonopods & $7.40 \times 10^{-3}$ & $1.22 \times 10^{11}$ & $3.10 \times 10^{7}$ & $3.78 \times 10^{18}$ & $2.97 \times 10^{4}$ \\
\hline Crustacea & 0.045 & $7.38 \times 10^{11}$ & $3.10 \times 10^{7}$ & $2.29 \times 10^{18}$ & $1.80 \times 10^{7}$ \\
\hline Chinese white dolphin & $2.28 \times 10^{-3}$ & $3.75 \times 10^{10}$ & $6.42 \times 10^{7}$ & $2.41 \times 10^{18}$ & $1.89 \times 10^{6}$ \\
\hline Birds & $8.94 \times 10^{-3}$ & $1.47 \times 10^{11}$ & $1.03 \times 10^{8}$ & $1.52 \times 10^{19}$ & $1.19 \times 10^{7}$ \\
\hline Bacteria & 0.164 & $2.70 \times 10^{12}$ & $1.10 \times 10^{7}$ & $2.97 \times 10^{16}$ & $2.33 \times 10^{4}$ \\
\hline Biodiversity & 5,713 species & & $2.43 \times 10^{19}$ & $1.39 \times 10^{23}$ & $1.09 \times 10^{11}$ \\
\hline Total & & & & $1.48 \times 10^{23}$ & $1.16 \times 10^{11}$ \\
\hline
\end{tabular}

Total area of the bay is $984 \mathrm{~km}^{2}$ for most components occupied except for mangrove in $2 \mathrm{~km}^{2}$ and macrobenthos (intertidal) in 129 $\mathrm{km}^{2}$.

Table 2 Eco-exergy analysis of marine ecosystem in Xiamen Bay in 2010 [28].

\begin{tabular}{llllll}
\hline Components & $\begin{array}{l}\text { Dry weight } \\
\left(\mathrm{g} / \mathrm{m}^{2}\right)\end{array}$ & $\begin{array}{l}\text { Turnover rates } \\
\text { (Times/year) }\end{array}$ & Weight $\beta$ & $\begin{array}{l}\text { Eco-exergy } \\
(\mathrm{kJ} / \text { year })\end{array}$ & $\begin{array}{l}\text { Ex dollar } \\
(\mathrm{RMB} / \text { year })\end{array}$ \\
\hline Biodetritus & $1.04 \times 10^{3}$ & 1 & 1 & $1.91 \times 10^{13}$ & $1.82 \times 10^{9}$ \\
Phytoplankton & 3.36 & 230 & 20 & $2.84 \times 10^{14}$ & $2.72 \times 10^{10}$ \\
Mangroves & $4.89 \times 10^{4}$ & 0.03 & 393 & $2.31 \times 10^{13}$ & $2.21 \times 10^{9}$ \\
Zooplankton & 0.106 & 32 & 210 & $1.31 \times 10^{13}$ & $1.25 \times 10^{9}$ \\
Macrobenthos & 7.52 & 6.5 & 200 & $1.56 \times 10^{14}$ & $1.50 \times 10^{10}$ \\
Macrobenthos (intertidal) & 138 & 6.5 & 200 & $4.30 \times 10^{14}$ & $4.11 \times 10^{10}$ \\
Meiofauna & 0.046 & 6.57 & 133 & $7.40 \times 10^{11}$ & $7.07 \times 10^{7}$ \\
Fish & 0.144 & 2 & 499 & $2.64 \times 10^{12}$ & $2.53 \times 10^{8}$ \\
Siphonopods & $7.40 \times 10^{-3}$ & 3.1 & 310 & $1.31 \times 10^{11}$ & $1.25 \times 10^{7}$ \\
Crustacea & 0.0448 & 5 & 232 & $9.56 \times 10^{11}$ & $9.14 \times 10^{7}$ \\
Chinese white dolphin & $2.28 \times 10^{-3}$ & 0.045 & 2,127 & $4.01 \times 10^{9}$ & $3.83 \times 10^{5}$ \\
Birds & $8.94 \times 10^{-3}$ & 0.06 & 980 & $9.68 \times 10^{9}$ & $9.25 \times 10^{5}$ \\
Bacteria & 0.164 & 1,400 & 8.5 & $3.59 \times 10^{13}$ & $3.43 \times 10^{9}$ \\
\hline Total & \multicolumn{7}{r}{} & & $9.67 \times 10^{14}$ & $9.24 \times 10^{10}$
\end{tabular}

Total area of the bay is $984 \mathrm{~km}^{2}$ for most components occupied except for Mangrove in $2 \mathrm{~km}^{2}$ and Macrobenthos (intertidal) in 129 $\mathrm{km}^{2} . \beta$ values are from Jørgensen’ works [25-27, 29]. Biodetritus is in dynamic equilibrium as in the assumption, so its turnover rate could be defined as 1 [25-27]. 


\section{Conclusions}

The concept, implication, approach and methods of EIV have been proposed in this article, including:

(1) EIV is an objective value expressed solely by ecosystem itself, independent with man, man's will and preferences, and valued as an end in itself to achieve higher end. It is ecosystem value its due;

(2) EIV includes the existence, structures, functions and processes of ecosystem as a whole, including the sum of its substance, energy and information, and consists of existence value and work capacity (a creative value of ecosystem);

(3) Energy approach and the methods of emergy analysis and eco-exergy analysis were proposed to evaluate EIV and to express its existence value and work capacity, the representation of stock and flow of EIV, respectively.

Case study indicated that the EIV of marine ecosystem in Xiamen Bay is much higher than its ESV and marine industry GDP of Xiamen city. EIV in unit area is more than 10 times of the average global ESV in estuaries. It shows that EIV is a more rational value, and implies a potential undervaluation to ecosystem value by ESV concept and approach.

The authors think that existence of ecosystem is a basis. No existence would be no function, no work from ecosystem and then no service to human-being. ESV is only the work of ecosystem to human-being, a partial ecosystem work rather than its real and whole value. Use of the service is intrinsically a human centered process relying largely on socio-economic data and to a lesser degree on biophysical information as mentioned by TEEB. In other word, due to its under-valuating ecosystem, as a result, ESV may mislead decision-making process. It, of course, results in that ecological degradation continues to accelerate. EIV is an objective value of ecosystem, can just conserve ecosystem by using it, and support decision-making towards sustainability.

\section{Acknowledgments}

This research project is financially supported by the fundamental research funds for the Directly Affiliated Universities in China (the Fundamental Innovation Research, Grant No. 2011121008, Xiamen University) and the National Natural Science Foundation of China (Project \#41376114). The authors appreciate professor Paolo F. Ricci for his contributions in the concept discussion in the beginning of this research.

\section{References}

[1] Costanza, R., D’Arge, R., De Groot, R., Farberk, S., Grasso, M., Hannon, B., Limburg, K., Naeem, S., O’Neill, R. V., Paruelo, J., Raskin, R. G., Suttonkk, P., and Van Den Belt, M. 1997. "The Value of the World's Ecosystem Services and Natural Capital.” Nature 387: 253-60.

[2] Burkhard, B., Petrosillo, I., and Costanza, R. 2010. "Ecosystem Services-Bridging Ecology, Economy and Social Sciences.” Ecological Complexity 7 (3): 257-9.

[3] Liu, Y., Zhang, L. P., and Hong, H. S. 2001. "Studies on Strategic Environmental Assessment for Sustainable Development in Coastal Zone.” China Environmental Science 21 (1): 45-8. (in Chinese)

[4] Chen, W. Q., Hong, H. S., Liu, Y., Zhang, L. P., Hou, X. F., and Raymond, M. 2004. "Recreation Demand and Economic Value: An Application of Travel Cost Method for Xiamen Island.” China Economic Review 15 (4): 398-406.

[5] Chen, B., and Zhang, L. P. 2003. "Practice on Strategic Environmental Assessment of Harbor Planning." Shanghai Environmental Science 22 (12): 1013-6. (in Chinese)

[6] Huang, X. Q., Wang, J. H., Jiang, X. S., Fang, J. M., and Zhang, L. P. 2008. Marine Environmental Capacity and Total Pllutant Control in Xiangshan Bay. Beijing: Ocean Press. (in Chinese)

[7] Wang, X., Chen, W. Q., Zhang, L. P., Jin, D., and Lu, C. Y. 2010. "Estimating the Ecosystem Service Losses from Proposed Land Reclamation Projects: A Case Study in Xiamen.” Ecological Economics 69 (12): 2549-56.

[8] Wang, G. H., Fang, Q. H., Zhang, L. P., Chen, W. Q., Cheng, Z. M., and Hong, H, S. 2010. "Valuing the Effects of Hydropower Development on Watershed Ecosystem Service: Case Studies in the Jiulong River Watershed, Fujian Province, China.” Estuarine, Coastal and Shelf Science 86 (3): 363-8. 
[9] Wu, X. X., Cai, Y. R., Chen, W. Q., and Zhang, L. P. 2014. "Eco-compensation for Coastal Principal Function Zoning in Xiamen Bay.” Advanced Materials Research 869-870: 683-90.

[10] Melathopoulos, A. P., and Stoner, A. M. 2015. "Critique and Transformation: On the Hypothetical Nature of Ecosystem Service Value and Its Neo-Marxist, Liberal and Pragmatist Criticisms.” Ecological Economics 117: 173-81.

[11] Dietz, T., Fitzgerald, A., and Shwom, R. 2005. "Environmental Values.” Annu. Rev. Environ. Resour. 30: 335-72.

[12] Davidson, M. 2013. “On the Relation between Ecosystem Services, Intrinsic Value, Existence Value and Economic Valuation.” Ecological Economics 95: 171-7.

[13] O'Neill, J. 1992. "The Varieties of Intrinsic Value.” The Monist 75 (2): 119-37.

[14] Millennium Ecosystem Assessment (MA). 2003. Ecosystems and Human Well-Being: A Framework for Assessment. Washington, DC: Island Press.

[15] The Economics of Ecosystems \& Biodiversity (TEEB). 2010. The Economics of Ecosystems and Biodiversity Ecological and Economic Foundations, edited by Kumar, P. London and Washington: Earthscan.

[16] Wikipedia. “Ecosystem.” Accessed December 2015. https://en.wikipedia.org/wiki/Ecosystem.

[17] Odum, H. T. 1983. System Ecology: An Introduction. New York: John Willey \& Sons, 644.

[18] Naeem, S., Duffy, J. E., and Zavaleta, E. 2012. "The Functions of Biological Diversity in an Age of Extinction.” Science 336: 1401-6.
[19] Odum, H. T. 1988. "Self-Organization, Transformity and Information.” Science 242: 1132-9.

[20] Odum, H. T. 1996. Environmental Accounting: Emergy and Environmental Decision Making. New York: John Wiley \& Sons.

[21] Brown, M. T., and Herendeen, R. A. 1996. "Embodied Energy Analysis and Emergy Analysis: A Comparative View.” Ecological Economics 19 (3): 219-35.

[22] Brown, M. T., and Ulgiati, S. 1999. "Emergy Evaluation of the Biosphere and Natural Capital.” AMBIO 28 (6): 1-15.

[23] Wikipedia. "Exergy.” Accessed December 2015. https://en.wikipedia.org/wiki/Exergy.

[24] Jørgensen, S. E., Ladegaard, N., Debeljak, M., and Marques, J. C. 2005. "Calculations of Exergy for Organisms.” Ecological Modelling 185 (2-4): 165-75.

[25] Jørgensen, S. E. 2006. Eco-exergy as Sustainability. Southampton: WIT Press.

[26] Jørgensen, S. E. 2007. "Evolution and Exergy." Ecological Modelling 203 (3-4): 490-4.

[27] Jørgensen, S. E., and Nielsen, S. N. 2007. “Application of Exergy as Thermodynamic Indicator in Ecology.” Energy 32 (5): 673-85.

[28] Xu, H. N., Sheng, H. X., and Zhang, L. P. 2014. "Evaluation of Marine Ecosystem Intrinsic Value-A Case Study of Xiamen Bay." Journal of Applied Oceanography 33 (4): 585-93. (in Chinese)

[29] Jørgensen, S. E. 2010. "Ecosystem Services, Sustainability and Thermodynamic Indicators." Ecological Complexity 7 (3): 311-3.

[30] Attfield, R. 1998. "Existence Value and Intrinsic Value.” Ecological Economics 24 (2-3): 163-8. 